\title{
Retrospective single-surgeon study of 1123 consecutive cases of anterior cervical discectomy and fusion: a comparison of clinical outcome parameters, complication rates, and costs between outpatient and inpatient surgery groups, with a literature review
}

\author{
Jack Mullins, BS, ${ }^{1}$ Mirza Pojskić, MD, ${ }^{2}$ Frederick A. Boop, MD, ${ }^{3,4}$ and \\ Kenan I. Arnautović, MD, PhD ${ }^{3,4}$ \\ ${ }^{1}$ College of William \& Mary, Williamsburg, Virginia; 2 Department of Neurosurgery, University of Marburg, Germany; ${ }^{3}$ Semmes \\ Murphey Neurologic \& Spine Institute; and ${ }^{2}$ Department of Neurosurgery, University of Tennessee Health Science Center, \\ Memphis, Tennessee
}

OBJECTIVE Outpatient anterior cervical discectomy and fusion (ACDF) is becoming more common and has been reported to offer advantages over inpatient procedures, including reducing nosocomial infections and costs, as well as improving patient satisfaction. The goal of this retrospective study was to evaluate and compare outcome parameters, complication rates, and costs between inpatient and outpatient ACDF cases performed by 1 surgeon at a single institution.

METHODS In a retrospective study, the records of all patients who had undergone first-time ACDF performed by a single surgeon in the period from June 1,2003, to January 31, 2016, were reviewed. Patients were categorized into 2 groups: those who had undergone ACDF as outpatients in a same-day surgical center and those who had undergone surgery in the hospital with a minimum 1-night stay. Outcomes for all patients were evaluated with respect to the following parameters: age, sex, length of stay, preoperative and postoperative pain (self-reported questionnaires), number of levels fused, fusion, and complications, as well as the presence of risk factors, such as an increased body mass index, smoking, and diabetes mellitus.

RESULTS In total, 1123 patients were operated on, 485 (43\%) men and 638 (57\%) women, whose mean age was 50 years. The mean follow-up time was 25 months. Overall, 40.5\% underwent 1-level surgery, 34.3\% 2-level, 21.9\% 3-level, and $3.2 \%$-level. Only 5 patients had nonunion of vertebrae; thus, the fusion rate was $99.6 \%$. Complications occurred in 40 patients (3.6\%), with 9 having significant complications (0.8\%). Five hundred sixty patients $(49.9 \%)$ had same-day surgery, and 563 patients (50.1\%) stayed overnight in the hospital. The inpatients were older, were more commonly male, and had a higher rate of diabetes. Smoking status did not influence the length of stay. Both groups had a statistically significant reduction in pain (expressed as a visual analog scale score) postoperatively with no significant difference between the groups. One- and 2-level surgeries were done significantly more often in the outpatient setting $(p<0.001)$.

The complication rate was $4.1 \%$ in the outpatient group and $3.0 \%$ in the inpatient group; there was no statistically significant difference between the 2 groups $(p=0.339)$. Significantly more complications occurred with 3 - and 4-level surgeries than with 1 - and 2-level procedures ( $p<0.001$, chi-square test). The overall average inpatient cost for commercial insurance carriers was $26 \%$ higher than those for outpatient surgery.

CONCLUSIONS Anterior cervical discectomy and fusion is safe for patients undergoing 1- or 2-level surgery, with a very significant rate of pain reduction and fusion and a low complication rate in both clinical settings. Outpatient and inpatient groups undergoing 3- or 4-level surgery had an increased risk of complications (compared with those undergoing 1- or 2-level surgery), with a negligible difference between the 2 groups. This finding suggests that these procedures can also be included as standard outpatient surgery. Comparable outcome parameters and the same complication rates between inpatient and outpatient groups support both operative environments.

https://thejns.org/doi/abs/10.3171/2017.10.SPINE17938

KEYWORDS ACDF; complication rate; inpatient surgery; outpatient surgery; cervical

ABBREVIATIONS ACDF = anterior cervical discectomy and fusion; $A$ SA = American Society of Anesthesiologists; BMI = body mass index; LOS = length of stay; NIS = National (Nationwide) Inpatient Sample; NSQIP = National Surgical Quality Improvement Program; VAS = visual analog scale.

SUBMITTED August 29, 2017. ACCEPTED October 17, 2017.

INCLUDE WHEN CITING Published online March 30, 2018; DOI: 10.3171/2017.10.SPINE17938. 
$\mathrm{A}$ NTERIOR cervical discectomy and fusion (ACDF) is considered the gold standard for many degenerative diseases of the cervical spine because of its relative simplicity, minimal risk, and reliability. ${ }^{8}$ It was first described by several authors in $1958^{5,31}$ and has become established as one of the most common spine procedures. A recent population-based observational study revealed a steady increase in cervical spine surgeries in both inpatient and outpatient settings. ${ }^{3}$

The increasing interest in cost-saving strategies has shifted many medical procedures to outpatient and ambulatory surgery centers. ${ }^{1}$ Ambulatory surgery comprised $9 \%$ (5.6 cases per 100,000 capita) of all cervical procedures in 2005 and $13 \%$ (9.0 cases per 100,000 capita) in 2009, constituting a $60.5 \%$ increase, whereas inpatient surgeries increased $8.7 \%$ over the same period. ${ }^{3}$ The safety of outpatient surgery has been demonstrated in spine surgery. ${ }^{6,24}$ In addition, the facility fees for ambulatory surgery centers are about $70 \%$ of those in the inpatient hospital setting. ${ }^{21}$ Thus, outpatient single-level ACDF procedures are becoming more common and offer advantages, such as reduced nosocomial infections and costs and improved patient satisfaction. ${ }^{12,13}$

Several studies have analyzed outcomes and complication rates for outpatient ACDF, while others have compared inpatient and outpatient ACDF. Four studies were based on an analysis of the American College of Surgeons National Surgical Quality Improvement Program (NSQIP) database. ${ }^{1,10,13,16,18,19,21,25,29,32,34,36}$

Here, we conducted the first single-institution, singlesurgeon comparison of outcomes between inpatient and outpatient ACDF with the advantage of diminishing the discrepancies that can arise from differences in the experience, technique, treatment protocol, and expertise of different surgeons. Like other authors, we analyzed 1- and 2-level surgeries, but we also evaluated patients who had undergone 3- and 4-level surgeries. For the first time, 3-level surgery was established as a standard procedure in the outpatient setting. The goal of this retrospective study was to evaluate and compare outcomes, complication rates, and costs between inpatient and outpatient ACDF procedures done by a single surgeon. We also reviewed the literature comparing outcome parameters between inpatient and outpatient ACDF.

\section{Methods}

After obtaining study approval from the appropriate hospital institutional review board (Baptist Memorial Hospital/Semmes Murphey Clinic), we evaluated the records for all patients who had undergone first-time ACDF for cervical radiculopathy and/or myelopathy due to degenerative disc disease and/or cervical spinal canal stenosis. Over a 13-year period (from June 1, 2003, to January 31, 2016), surgeries were performed by the senior author, who used a standard anterior approach from the left side. Fusion was achieved using cadaver allografts (Medtronic Inc.) with the Vision Elite titanium plate and various screws (Medtronic Inc.). Operative reports, hospital and outpatient clinic charts, and radiographic studies were independently reviewed by 2 individuals. Differences in findings were adjudicated during a review conference that included all authors.

The patients were categorized into 2 groups: those who had undergone ACDF as an outpatient procedure (sameday discharge) and those who had undergone surgery in the metropolitan area hospital (inpatients) with a minimum 1-night stay (overnight stay). General indications for the procedure were pain that had not resolved with conservative therapy (pain medication and at least 8 weeks of physical therapy) and the presence of neurological deficits. The decision to perform surgery in either the inpatient or outpatient setting was based on several indicators, most importantly, the presence of comorbidities and the type of health insurance. Patients who had Medicare were admitted to stay overnight. Furthermore, older patients (age > 65 years) and patients with comorbidities who had a preoperative American Society of Anesthesiologists (ASA) physical status classification of III or IV stayed overnight. Patients who went home on the same day were observed for up to 6 hours postoperatively and were followed up via phone interview for 4 postoperative days.

Outcomes for all patients were evaluated with respect to the following parameters: age, sex, length of stay (LOS), preoperative and postoperative pain (both from self-reported questionnaires), number of levels fused, fusion, and complications, as well as the presence of risk factors, such as increased body mass index (BMI), smoking, and diabetes mellitus. Outcomes for the inpatient group were compared with those for the outpatient group. A cost analysis was also done for both groups.

\section{Statistical Analysis}

Data were recorded using descriptive statistical methods. The Mann-Whitney U-test was used to compare samples. The chi-square test and Fisher's exact test were used to assess differences between groups. The level of significance was set at $p=0.05$. Statistical analysis was performed using MedCalc Statistical Software version 14.12.0 (MedCalc Software bvba).

\section{Results \\ Overall Patient Characteristics}

Overall patient characteristics are summarized in Table 1. The median follow-up was 25 months (SD 5.63, range 11-56 months).

\section{Age and Sex}

Overall, 1123 patients were operated on, 485 (43\%) of whom were men and 638 (57\%) of whom were women. The median patient age was 50 years (Fig. 1).

\section{Risk Factors}

Overall, 172 patients (15.3\%) had diabetes mellitus, which affected patients equally by sex. Three hundred eighty-nine patients $(34.6 \%)$ used tobacco; among these patients, there were significantly more men $(192,17 \%$ of overall group; $p=0.002$, Fisher's exact test). According to anthropometric measurements, men were significantly taller and heavier, but there were no significant differences between the sexes in terms of BMI characteristics. 
TABLE 1. General characteristics of patients who underwent ACDF

\begin{tabular}{|c|c|c|c|c|}
\hline \multirow[b]{2}{*}{ Parameter } & \multicolumn{2}{|c|}{ Sex } & \multirow[b]{2}{*}{ Overall } & \multirow[b]{2}{*}{$p$ Value } \\
\hline & Male & Female & & \\
\hline No. of patients & 485 & 638 & 1123 & \\
\hline Median age in yrs (IQR) & $51(44-58)$ & $49(43-57)$ & $50(43-58)$ & $0.090 \dagger$ \\
\hline \multicolumn{5}{|l|}{ Risk factor (no. [\%]) } \\
\hline Diabetes mellitus & $76(15.67)$ & $96(15.05)$ & $172(15.32)$ & $0.802 \ddagger$ \\
\hline Smoking & $192(39.59)$ & $197(30.88)$ & $389(34.64)$ & $0.002 \ddagger$ \\
\hline Total & $268(55.26)$ & $293(45.92)$ & $561(49.96)$ & \\
\hline Median height in inches (IQR) & $70(68-72)$ & $64(62-66)$ & $67(64-69)$ & $<0.001 \dagger$ \\
\hline Median weight in Ibs (IQR) & $202.1(178.3-232)$ & $173.8(150-205)$ & $187.9(160-215)$ & $<0.001 \dagger$ \\
\hline Median BMI (IQR) & $29.5(26.5-32.9)$ & $30.2(26.1-34.7)$ & $29.8(26.3-33.8)$ & $0.519 \dagger$ \\
\hline Surgical level (no. [\%]) & & & & $0.234^{*}$ \\
\hline 1 & $198(40.82)$ & $257(40.28)$ & $455(40.52)$ & \\
\hline 2 & $158(32.58)$ & $228(35.74)$ & $386(34.34)$ & \\
\hline 3 & $108(22.27)$ & $138(21.63)$ & $246(21.91)$ & \\
\hline 4 & $21(4.33)$ & $15(2.35)$ & $36(3.21)$ & \\
\hline $\operatorname{LOS}($ no. $[\%])$ & & & & $0.132 \ddagger$ \\
\hline Outpatient & $229(47.22)$ & $331(51.88)$ & $560(49.87)$ & \\
\hline Inpatient & $256(52.78)$ & $307(48.12)$ & $563(50.13)$ & \\
\hline $\operatorname{LOS}($ no. $[\%])$ & & & & $0.009 \S$ \\
\hline Same day & $229(47.22)$ & $331(51.88)$ & $560(49.87)$ & \\
\hline 1 night & $224(46.19)$ & $286(44.83)$ & $510(45.41)$ & \\
\hline 2 nights & $16(3.30)$ & $16(2.51)$ & $32(2.85)$ & \\
\hline$\geq 3$ nights & $16(3.30)$ & $5(0.78)$ & $21(1.87)$ & \\
\hline Median FU in mos (IQR) & $25(21-30)$ & $24(21-29)$ & $25(21-30)$ & $0.617 \dagger$ \\
\hline Median preop VAS pain score (IQR) & $7.5(6-8.5)$ & $8(7-9)$ & $7.75(6-9)$ & $<0.001 \dagger$ \\
\hline Median postop VAS pain score (IQR) & $0(0-2)$ & $0(0-2)$ & $0(0-2)$ & \\
\hline \multicolumn{5}{|c|}{$\begin{array}{l}\text { FU = follow-up. } \\
\text { Boldface type indicates statistical significance. } \\
\text { † Mann-Whitney U-test. } \\
\text { † Fisher's exact test. } \\
\text { * Levels } 1 \text { and } 2 \text { compared with levels } 3 \text { and } 4 \text {, chi-square test. } \\
\text { § Chi-square test. }\end{array}$} \\
\hline
\end{tabular}

Pain

Each patient's pain level was assessed using a self-administered, self-reported visual analog scale (VAS) before and after surgery (Fig. 2). Preoperative pain was significantly higher in women (median 8, IQR 7-9) than in men ( $p<0.001$, Mann-Whitney U-test; Table 1). Both men and women had a significant reduction in pain after surgery ( $\mathrm{p}$ $<0.001$, Wilcoxon test).

\section{Levels of Surgery}

Overall, $40.5 \%$ of patients underwent 1-level surgery, 34.3\% 2-level, 21.9\% 3-level, and 3.2\% 4-level (Table 1).

Fusion

Fusion was assessed with lateral radiographs of the cervical spine during follow-up visits and was recorded when it occurred. A fusion was considered solid when osseous trabeculae were seen to bridge the disc space on the lateral radiograph ${ }^{30}$ and there was no motion on standard flexion and extension lateral spine radiographs. An independent

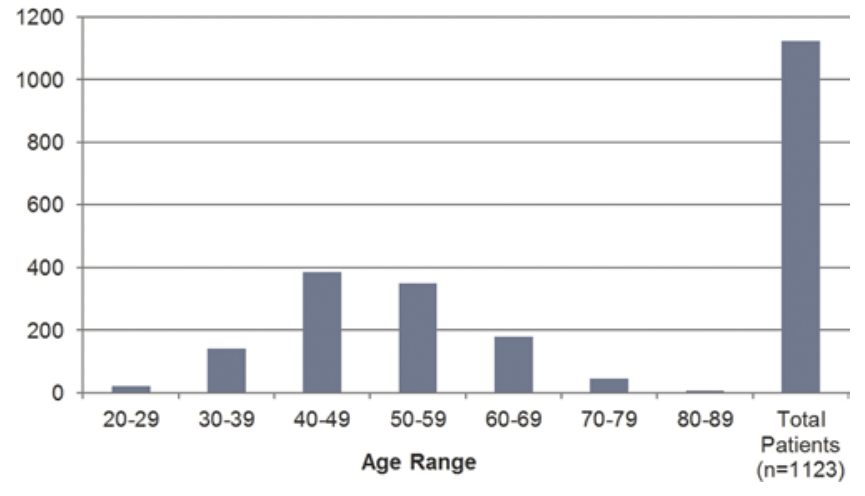

FIG. 1. Age distribution (x-axis, in years) of the cohort (y-axis, number of patients). Figure is available in color online only. 


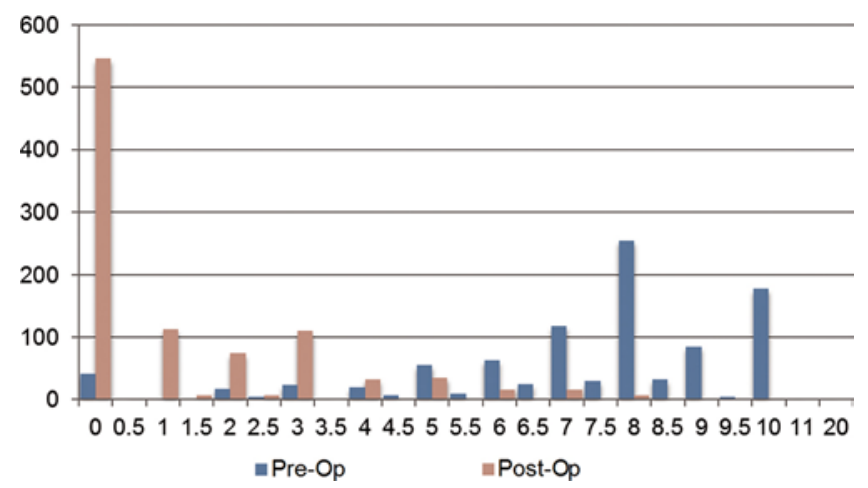

FIG. 2. Comparison of preoperative and postoperative pain levels ( $x-$ axis, VAS score) in all patients ( $y$-axis, number of patients). Figure is available in color online only.

neuroradiologist who is not a coauthor of this study reviewed the radiographs. Computed tomography scanning of the cervical spine was performed if there were clinical indicators (i.e., neck pain) of passible underlying nonunion, when there were radiological signs of pseudarthrosis, or if radiographic results were inconclusive. Five patients $(0.45 \%)$ had nonunion during the follow-up; thus, the fusion rate was $99.56 \%$. Two of these patients were male, smokers, and outpatients, and 3 (1 female and 2 males) were nonsmokers and inpatients. Three patients underwent additional surgery because of nonunion, 1 patient had a ventral revision, and 2 patients underwent additional posterior fusion. These patients were not double counted in the study.

\section{Complications}

Complications, including nonunion, occurred in 40 patients (3.6\%; Table 2). Seven patients (0.62\%) who developed significant temporary swallowing problems postoperatively were included in the complication rate even though the problem was resolved conservatively during follow-up. Major complications were defined as any septic, cardiac, pulmonary, or cerebrovascular complications, as well as deep vein thrombosis, pulmonary embolism, or a return to the operating suite..$^{10}$

Despite these complications, all patients had a significant reduction in preoperative pain after surgery $(\mathrm{p}<$ 0.001 , Wilcoxon test; Table 2). The most common complication was infection in 11 patients $(0.98 \%)$, followed by hematoma in $9(0.80 \%)$, Horner syndrome in $5(0.45 \%)$, nonunion in $5(0.45 \%)$, lower plate-screw breakage in 2 $(0.18 \%)$, and screw pullout in $1(0.09 \%)$. The 9 patients with neck hematomas were returned to the operating room. Two outpatients had a same-day reoperation for the hematoma (2-level and 4-level ACDF, respectively), and

TABLE 2. Characteristics of patients with complications following ACDF

\begin{tabular}{|c|c|c|c|c|}
\hline \multirow[b]{2}{*}{ Parameter } & \multicolumn{2}{|c|}{ Complications } & \multirow[b]{2}{*}{ Overall } & \multirow[b]{2}{*}{ p Value } \\
\hline & No & Yes & & \\
\hline No. of patients & 1083 & 40 & 1123 & \\
\hline Sex (no. [\%]) & & & & $0.005^{*}$ \\
\hline Male & $459(42.4)$ & $26(65)$ & $485(43.2)$ & \\
\hline Female & $624(57.6)$ & $14(35)$ & $638(56.8)$ & \\
\hline \multicolumn{5}{|l|}{ Risk factor (no. [\%]) } \\
\hline Diabetes mellitus & $163(15.0)$ & $9(22.5)$ & $172(15.3)$ & $0.186 \dagger$ \\
\hline Smoking & $375(34.6)$ & $14(35)$ & $389(34.6)$ & $>0.990 \ddagger$ \\
\hline Median height in inches (IQR) & $66.5(64-69)$ & $68(67-69)$ & $67.25(64-69)$ & $0.265 \dagger$ \\
\hline Median weight in Ibs (IQR) & $187.8(160-215)$ & $185(153.7-232)$ & $186.4(160-215)$ & $0.819 \dagger$ \\
\hline Median BMI (IQR) & $29.9(26.4-33.9)$ & $28.7(25-33.7)$ & $29.3(26.3-33.8)$ & $0.283 \dagger$ \\
\hline Surgical level (no. [\%]) & & & & $<0.001 \S$ \\
\hline 1 & $447(41.3)$ & $8(20)$ & $455(40.5)$ & \\
\hline 2 & $375(34.6)$ & $11(27.5)$ & $386(34.4)$ & \\
\hline 3 & $232(21.4)$ & $14(35)$ & $246(21.9)$ & \\
\hline 4 & $29(2.7)$ & 7 (17.5) & $36(3.2)$ & \\
\hline LOS (no. [\%]) & & & & $0.339 \ddagger$ \\
\hline Outpatient & $537(49.6)$ & $23(57.5)$ & $560(49.9)$ & \\
\hline Inpatient & $546(50.4)$ & $17(42.5)$ & $563(50.1)$ & \\
\hline Median FU in mos (IQR) & $25(21-30)$ & $28(22-34)$ & $25(21-30)$ & $0.026 \dagger$ \\
\hline Median preop VAS pain score (IQR) & $8(6-9)$ & $8(6.8-9)$ & $8(6-9)$ & $0.375 \dagger$ \\
\hline Median postop VAS pain score (IQR) & $0(0-2)$ & $1(0-3)$ & $0.5(0-2)$ & $0.039 \dagger$ \\
\hline $\begin{array}{l}\text { Boldface type indicates statistical significance } \\
\text { * Chi-square test. } \\
\text { † Mann-Whitney U-test. } \\
\text { † Fisher's exact test. } \\
\S \text { Levels } 1 \text { and } 2 \text { compared with levels } 3 \text { and }\end{array}$ & square test. & & & \\
\hline
\end{tabular}


TABLE 3. Patient characteristics according to LOS

\begin{tabular}{lccrr}
\hline \multicolumn{1}{c}{ Parameter } & Outpatient (same-day discharge) & Inpatient (overnight stay) & Overall & $p$ Value \\
\hline No. of patients & 560 & 563 & 1123 & $<0.001$ \\
\hline Median age in yrs (IQR) & $47.5(41-55)$ & $53(46-62)$ & & \\
\hline Risk factor (no. [\%]) & $63(11.3)$ & $109(19.4)$ & $172(15.3)$ & $<0.001 \dagger$ \\
\hline \multicolumn{1}{l}{ Diabetes mellitus } & $211(37.7)$ & $178(31.6)$ & $389(34.6)$ & $0.501 \dagger$ \\
\hline Smoking & $67(63-70)$ & $66(64-69)$ & $66.5(64-69)$ & $0.381 \ddagger$ \\
\hline Median height in inches (IQR) & $185.6(158.8-216)$ & $188.5(160-213.3)$ & $187(160-215)$ & $0.928 \ddagger$ \\
\hline Median weight in Ibs (IQR) & $29.7(26.4-33.7)$ & $29.9(26.2-34.1)$ & $29.8(26.3-33.8)$ & $0.686 \ddagger$ \\
\hline Median BMI (IQR) & & & & $<0.001^{*}$ \\
\hline Surgical level (no. [\%]) & $246(43.9)$ & $209(37.1)$ & $455(40.5)$ & \\
\hline 1 & $198(35.4)$ & $188(33.4)$ & $386(34.4)$ & \\
\hline 2 & $110(19.6)$ & $136(24.2)$ & $246(21.9)$ & \\
\hline 3 & $6(1.1)$ & $30(5.3)$ & $36(3.2)$ & \\
\hline 4 & $26(22-30)$ & $24(21-29)$ & $25(21-30)$ & $0.001 \ddagger$ \\
\hline Median FU in mos (IQR) & $8(7-9)$ & $7(6-8)$ & $7.5(6-9)$ & $<0.001 \ddagger$ \\
\hline Median preop VAS pain score (IQR) & $0(0-2)$ & $0(0-2)$ & $0(0-2)$ & $0.713 \ddagger$ \\
\hline Median postop VAS pain score (IQR) & & & &
\end{tabular}

3 others (3-level, 3-level, and 2-level ACDF, respectively) were operated on 3,6, and 6 days after the initial surgery, respectively. Outpatients with neck hematomas were not counted as inpatients in our analysis. Four inpatients developed postoperative hematomas (3-level, 3-level, 1-level, and 4-level ACDF, respectively). They were operated on 1, 4,6 , and 7 days after the initial surgery.

Overall, complications occurred in $1.8 \%$ of patients who underwent 1-level surgery, $2.8 \%$ who had 2-level surgery, $5.7 \%$ who had 3-level surgery, and $19.4 \%$ with 4-level surgery. Significantly more complications occurred in patients who had 3- or 4-level surgery ( $p<0.001$, chi-square test; Table 2). Patients with complications had significantly greater postoperative pain (median VAS score 1, IQR $0-3 ; p=0.039$, Mann-Whitney U-test).

\section{Inpatient and Outpatient Characteristics and Outcome Comparisons}

Length of Stay

A total of 560 patients $(49.9 \%)$ were discharged home on the same day (Table 3). Of the remaining 563 patients (50.1\%), $510(90.6 \%)$ remained in the hospital for only 1 night and $96.27 \%$ left the hospital within 3 days. Only 21 patients stayed in the hospital 3 nights or more. Patients were kept in the hospital for medical reasons. The 2 longest LOSs for the inpatients were 10 days (infection) and 18 days (postural hypotension).

\section{General Patient Characteristics}

The general characteristics of both groups are shown in Table 3. There were significant differences in baseline characteristics and comorbidities between outpatients and inpatients. Because of the Medicare mandate, the inpa- tient group was older (53 vs 47.5 years, $p<0.001)$. Significantly more men remained in the hospital for 2 or more nights ( $p=0.010$, chi-square test). The 2 groups showed no differences in height, weight, or BMI. Younger patients went home the same day ( $p<0.001$, Mann-Whitney Utest) more often than the older patients. The older patients having surgery on 1-3 levels stayed in the hospital significantly longer ( $\mathrm{p}<0.001$, chi-square test). Those having 4-level surgery showed no significant differences in age according to the LOS.

Smoking did not affect the LOS after surgery. There was a higher rate of diabetes mellitus in the inpatient group. Of the 172 patients with diabetes (15.3\% of the overall group), 109 (63.4\% of all patients with diabetes) stayed in the hospital significantly longer ( $p<0.001$, Fisher's exact test).

\section{Levels of Surgery}

The number of fused levels differed between the inpatients and outpatients. Among the inpatients, 209 (37.1\%) underwent 1-level surgery, 188 (33.4\%) had 2-level surgery, $136(24.2 \%)$ had 3-level surgery, and $30(5.3 \%)$ had 4-level surgery.

In the outpatient group, 1-level surgery was the most common (246 patients [43.9\%]). Level C5-6 was the most common surgical site. Two-level surgery was performed in 198 patients (35.4\%), 3-level surgery in 110 (19.6\%), and 4-level surgery in $6(1.1 \%)$.

One- and 2-level surgeries were performed significantly more often in the outpatient setting, whereas 3- and 4-level surgeries were performed more often as inpatient procedures ( $\mathrm{p}<0.001$; Figs. 3-6).

\section{Pain}

Preoperative pain in the inpatient group was signifi- 


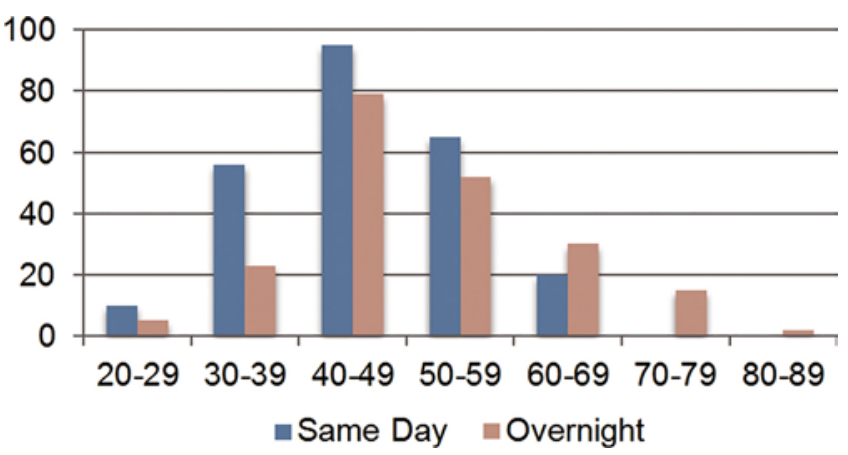

FIG. 3. Age distribution (in years, $x$-axis) for patients (number, $y$-axis) who underwent 1-level surgery, according to hospital LOS. Overnight = overnight stay; Same Day = same-day discharge. Figure is available in color online only.

cantly lower on the VAS scale than that in the outpatients $(\mathrm{p}<0.001)$. In both groups, pain was significantly reduced after surgery ( $p<0.001$, Wilcoxon test) with no significant differences between the groups.

\section{Complications}

The complication rate was $4.1 \%$ in the outpatient group and $3.0 \%$ among the inpatients. There was no statistically significant difference between these 2 groups $(p=0.339$; Fig. 7). Significantly more complications occurred in patients having 3- or 4-level surgery than in those having 1 - or 2-level surgery ( $\mathrm{p}<0.001$, chi-square test). Following 1 - and 2-level surgeries, outpatients had more complications than the inpatients, whereas after 3-level surgery inpatients had significantly more complications. Four-level surgery patients showed no difference in the number of complications between inpatient and outpatient groups ( $\mathrm{p}$ $=0.044$ ). A total of $1.76 \%$ of patients who had undergone 1-level surgery and $2.85 \%$ of patients who had undergone 2-level surgery experienced complications. Nine patients had neck hematomas (5 outpatients and 4 inpatients).

\section{Reoperations}

A total of 27 patients (2\%) were reoperated on during the follow-up for adjacent-segment disease. Those surgeries were not double counted as primary procedures. Eleven patients underwent posterior surgery, and 16 underwent anterior surgery. Sixteen patients had adjacentsegment disease above the level of the initial ACDF, and

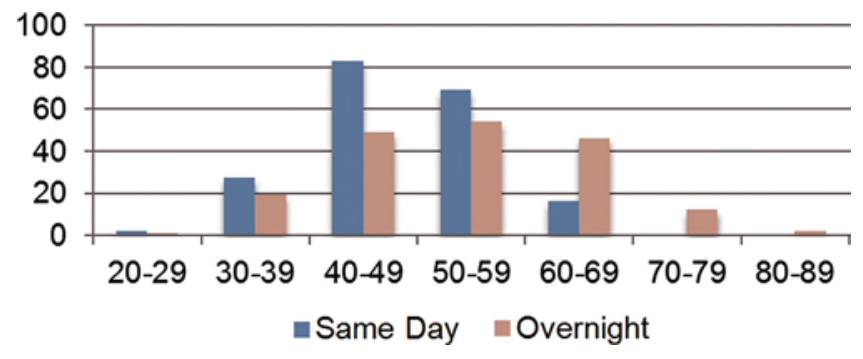

FIG. 4. Age distribution (in years, x-axis) for patients (number, y-axis) who underwent 2-level surgery, according to hospital LOS. Figure is available in color online only.

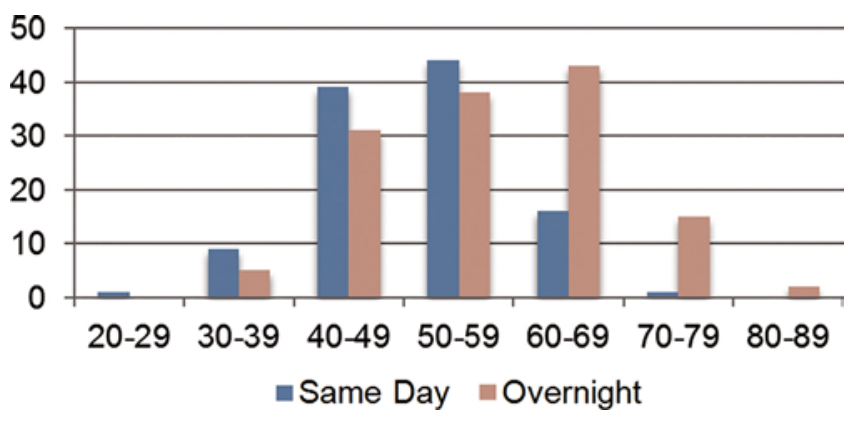

FIG. 5. Age distribution (in years, x-axis) for patients (number, y-axis) who underwent 3-level surgery, according to hospital LOS. Figure is available in color online only.

11 patients had adjacent-segment disease below the ACDF level.

Costs

To minimize the reimbursement collection bias, we compared data for the year 2015, including only commercial insurance carriers. Data were obtained from the chief financial officers of the outpatient and inpatient institutions separately. The average facility reimbursement collections for commercial insurance ACDF procedures were calculated by dividing total commercial insurance reimbursements for 2015 ACDF cases by the number of cases done that year. These reimbursements were for the operating room, instrumentation, anesthesia (excluding physician fees and facility costs), observation/hospital room, imaging, and pharmacy expenses. This calculation was done both for inpatient and for outpatient institutions, and the results were compared.

In the outpatient setting, the average reimbursement for treatment of an individual patient was $\$ 18,095$. In the inpatient setting, the average reimbursement per patient was $\$ 24,492$. The average difference in commercial insurance reimbursement was $\$ 6397$ in favor of the outpatient group. In other words, reimbursements for the outpatient group were $74 \%$ of those for the inpatient group.

\section{Distribution of Cases: Timeline}

After the senior author joined the practice (2003) and after the inauguration of the outpatient surgery center (2005), the total number of ACDF surgeries, including the outpatient cases, increased until 2007 and then re-

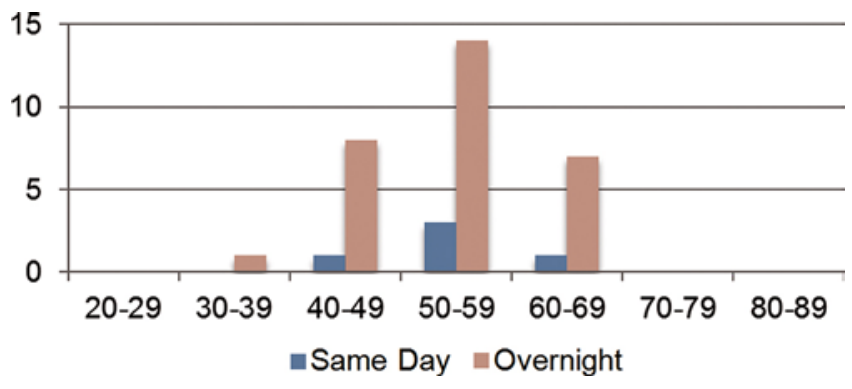

FIG. 6. Age distribution (in years, x-axis) for patients (number, y-axis) who underwent 4-level surgery, according to hospital LOS. Figure is available in color online only. 


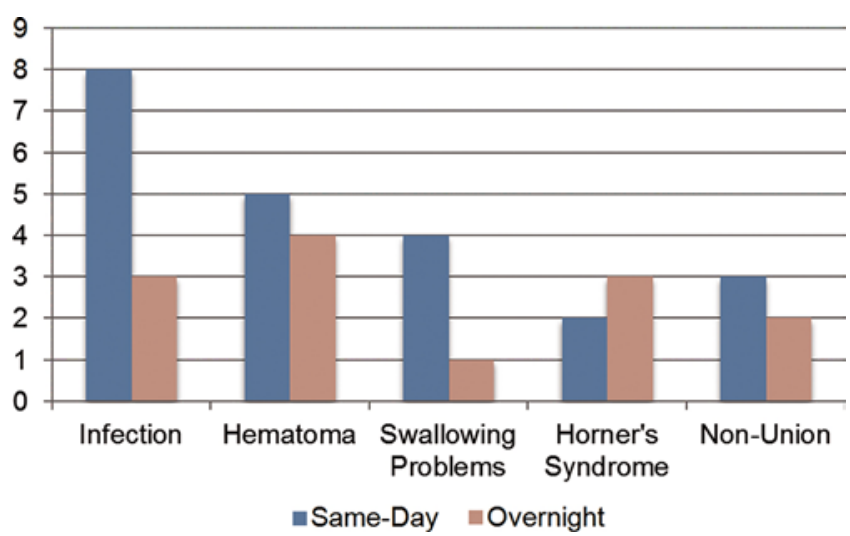

FIG. 7. Distribution of complications (number, y-axis) according to LOS. Figure is available in color online only.

mained relatively stable (after 2009) in terms of both the absolute number of cases done per year and the inpatient/ outpatient ratio (Fig. 8).

\section{Discussion}

To our knowledge, this is the first retrospective singlesurgeon, single-institution study of patients who had undergone ACDF in which the outcomes were compared between outpatient (same-day discharge) and inpatient (overnight stay) surgery. This is also the only study to evaluate clinical outcomes (pain reduction), radiological outcomes (fusion), and complication rates between the 2 groups. Furthermore, this is the first study to compare costs for both inpatient and outpatient procedures. Finally, this study establishes for the first time the safety of performing 3-level ACDF as an outpatient procedure.

In a literature review of PubMed, MEDLINE, and the Cochrane databases using the keywords "inpatient ACDF" and "outpatient ACDF," we identified a total of 12 peer-reviewed articles that compared different outcome

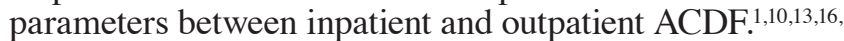
$18,20,21,25,29,32,34,36$ Four of these papers were multicenter propensity score-adjusted retrospective or prospective cohort studies of the NSQIP database..$^{10,13,18,21}$ Five studies were retrospective; 1 was prospective. Two studies were retrospective analyses of the National (Nationwide) Inpatient Sample (NIS) and/or the inpatient and ambulatory databases of 4 states (California, Florida, New Jersey, and New York). A summary of these studies is featured in Table 4.

In the study by Villavicencio and colleagues, the outpatient data were analyzed retrospectively and compared with a historical cohort developed from a meta-analysis. ${ }^{36}$ When we exclude the 4 cohort studies of the NSQIP database $^{10,13,18,21}$ and the study of Purger et al., ${ }^{25}$ our study is second to that of Adamson and associates in number of patients and is the only single-surgeon, single-institution study on ACDF to date. The studies by Silvers and colleagues $^{29}$ and Liu and associates ${ }^{16}$ had fewer than 110 patients each, which makes their results difficult to compare with the results of our study. The studies of Stieber et al. ${ }^{32}$ and Trahan et al. ${ }^{34}$ - which compared complication rates only between inpatient and outpatient $\mathrm{ACDF}$-were in-

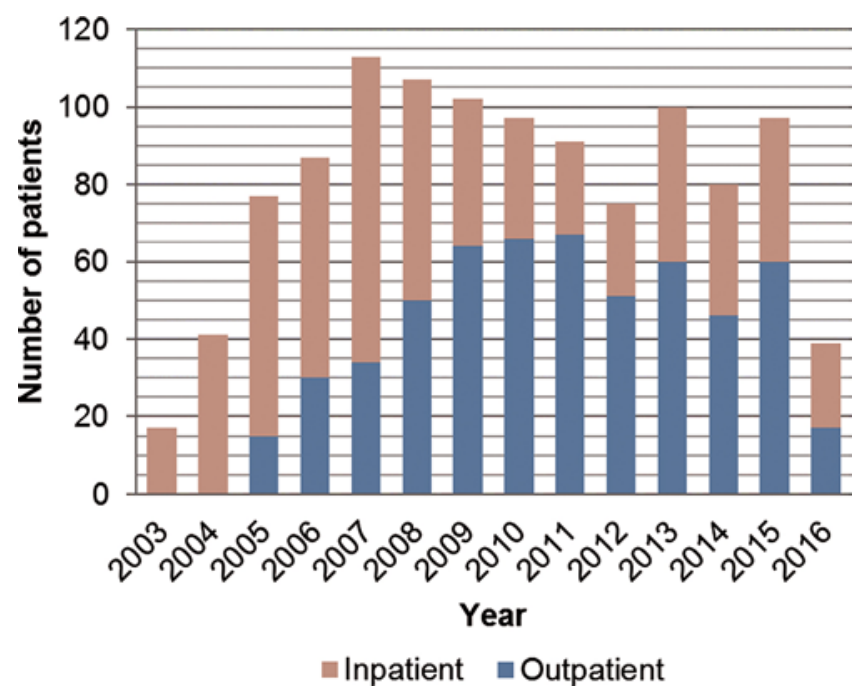

FIG. 8. Distribution of inpatients and outpatients in the 2003-2016 time period. Figure is available in color online only.

cluded in our literature review, although these studies also had fewer than 120 patients each, which again makes comparison with our study difficult.

\section{Inpatient and Outpatient Characteristics and Risk Factors}

In our study, the inpatient group was older (53 vs 47.5 years, $\mathrm{p}<0.001)$, and there were no differences in BMI between the outpatient and inpatient groups. This finding was comparable to those in most other studies, although our inpatient group was a bit younger than the inpatient group in the study by Adamson and colleagues (53 vs 56 years). ${ }^{1}$ The inpatient group in their study was older than the outpatient group, as was true in other studies. ${ }^{10,13,16}$ In a multicenter study by McGirt and associates, the inpatient group was older and consisted of more males and more patients with comorbidities, such as diabetes, ${ }^{21}$ which is consistent with our results. Although we found no differences between our inpatient and outpatient groups according to sex, significantly more male patients stayed in the hospital for 2 or more nights. The reason for this remains unclear. A possible explanation is that significantly more men were smokers. Furthermore, according to anthropometric measurements, the men were heavier, although there was no significant difference in BMI. Current data from the literature show that male sex portends a better ACDF outcome, relating this finding to greater muscle strength and endurance. ${ }^{22}$ In a recent study, female sex was identified as one of the factors contributing to an increased LOS following $\mathrm{ACDF}^{2}$ The retrospective nature of that study, given its low complication rate, does not exclude the possibility of a confounding bias when it comes to influence of sex on outcome. Unlike other studies, we did not analyze propensity scores to account for all of the differences that may have served as potential confounders. But because of our single-institution, single-surgeon study design and the fact that there were no differences in sex, smoking, and BMI between the inpatient and outpatient groups, we can state that these parameters had very little or no effect on the outcome. 
TABLE 4. Literature studies comparing inpatient and outpatient ACDF procedures

\begin{tabular}{|c|c|c|c|c|c|c|c|}
\hline \multirow[b]{2}{*}{$\begin{array}{l}\text { Authors \& } \\
\quad \text { Year }\end{array}$} & \multirow[b]{2}{*}{ Study Type } & \multirow[b]{2}{*}{ No. of Surgeons } & \multirow[b]{2}{*}{$\begin{array}{l}\text { Surgical } \\
\text { Levels }\end{array}$} & \multirow[b]{2}{*}{ No. of Patients } & \multicolumn{3}{|c|}{ Analysis of Outcome Parameters } \\
\hline & & & & & $\begin{array}{l}\text { Reduced } \\
\text { Pain }\end{array}$ & Fusion & Complication Rate \\
\hline $\begin{array}{l}\text { Silvers et } \\
\quad \text { al., } 1996\end{array}$ & Prospective & Not specified (>1) & $1 \& 2$ & $\begin{array}{l}109 \text { patients: } 53 \text { inpa- } \\
\text { tients, } 56 \text { outpatients }\end{array}$ & Yes & No & Inpatient $2 \%$, outpatient $2 \%$ \\
\hline $\begin{array}{l}\text { Stieber et } \\
\text { al., } 2005\end{array}$ & Retrospective & Not specified (>1) & $1 \& 2$ & $\begin{array}{l}90 \text { patients: } 60 \text { inpa- } \\
\text { tients, } 30 \text { outpatients }\end{array}$ & No & No & $\begin{array}{l}\text { Inpatient } 13 \% \text {, outpatient } \\
\quad 10 \%\end{array}$ \\
\hline $\begin{array}{l}\text { Villavicen- } \\
\text { cio et al., } \\
2007\end{array}$ & Retrospective & Multiple & $1 \& 2^{*}$ & $\begin{array}{l}739 \text { patients: } 633 \\
\text { inpatients, } \uparrow 106 \\
\text { outpatients }\end{array}$ & No & No & $\begin{array}{l}\text { Inpatient } 0.95 \% \text {, outpatient } \\
\quad 3.8 \%\end{array}$ \\
\hline $\begin{array}{l}\text { Liu et al., } \\
2009\end{array}$ & Retrospective & 2 & 1 & $\begin{array}{l}109 \text { patients: } 64 \text { inpa- } \\
\text { tients, } 45 \text { outpatients }\end{array}$ & Yes & No & Inpatient $3.7 \%$, outpatient $0 \%$ \\
\hline $\begin{array}{l}\text { Trahan et } \\
\text { al., } 2011\end{array}$ & Retrospective & $\begin{array}{l}\text { Multiple (surgeon } \\
\quad \& \text { supervised } \\
\text { residents) }\end{array}$ & $1 \& 2$ & $\begin{array}{l}117 \text { patients: } 58 \text { inpa- } \\
\text { tients, } 59 \text { outpatients }\end{array}$ & No & No & Inpatient $0 \%$, outpatient $1.4 \%$ \\
\hline $\begin{array}{l}\text { Martin et } \\
\text { al., } 2014\end{array}$ & $\begin{array}{l}\text { Multicenter propensity } \\
\text { score-adjusted retro- } \\
\text { spective cohort study } \\
\text { of NSQIP database }\end{array}$ & Multiple & 1 & $\begin{array}{l}2914 \text { patients: } 597 \\
\text { outpatients, } 2317 \\
\text { inpatients }\end{array}$ & No & No & $\begin{array}{l}\text { Inpatient } 2.9 \% \text {, outpatient } \\
\quad 1.3 \%\end{array}$ \\
\hline $\begin{array}{l}\text { McGirt et } \\
\text { al., } 2015\end{array}$ & $\begin{array}{l}\text { Multicenter propensity } \\
\text { score-adjusted retro- } \\
\text { spective cohort study } \\
\text { of NSQIP database }\end{array}$ & Multiple & $\begin{array}{l}\text { All levels w/ } \\
\text { median } \\
1.25 \pm 0.5\end{array}$ & $\begin{array}{l}7288 \text { patients: } 6120 \\
\text { inpatients, } 1168 \\
\text { outpatients }\end{array}$ & No & No & $\begin{array}{l}\text { Inpatient morbidity } 1.4 \% \text {, } \\
\text { outpatient morbidity } 3.1 \%\end{array}$ \\
\hline $\begin{array}{l}\text { Khanna et } \\
\text { al., } 2017\end{array}$ & $\begin{array}{l}\text { Multicenter propensity } \\
\text { score-adjusted retro- } \\
\text { spective cohort study } \\
\text { of NSQIP database }\end{array}$ & Multiple & 1 & $\begin{array}{l}6940 \text { patients: } 5162 \\
\text { inpatients, } 1778 \\
\text { outpatients }\end{array}$ & No & No & $\begin{array}{l}\text { Inpatient } 2.5 \% \text {, outpatient } \\
1.2 \%\end{array}$ \\
\hline $\begin{array}{c}\text { Fu et al., } \\
2017\end{array}$ & $\begin{array}{l}\text { Retrospective cohort } \\
\text { study of prospectively } \\
\text { collected data from } \\
\text { NSQIP database }\end{array}$ & Multiple & $1 \& 2$ & $\begin{array}{l}\text { 22,006 patients: } 4759 \\
\text { outpatients, } 17,247 \\
\text { inpatients }\end{array}$ & No & No & $\begin{array}{l}\text { Inpatient 3.94\%, outpatient } \\
\quad 1.47 \%\end{array}$ \\
\hline $\begin{array}{l}\text { Adamson } \\
\text { et al., } \\
2016\end{array}$ & Retrospective & Multiple & $1 \& 2$ & $\begin{array}{l}1484 \text { patients: } 1000 \\
\text { outpatients, } 484 \\
\text { inpatients }\end{array}$ & No & No & $\begin{array}{l}\text { 30-day readmission: inpatient } \\
2.9 \% \text { vs outpatient } 1.8 \% \text {; } \\
\text { 90-day readmission: in- } \\
\text { patient } 1.5 \% \text { vs outpatient } \\
1.3 \% ; 90 \text {-day reopera- } \\
\text { tion (same site) } 1 \text {-level: } \\
1 \text { inpatient }(0.4 \%), 1 \\
\text { outpatient }(0.2 \%) ; 90 \text {-day } \\
\text { reoperation (same site) } \\
2 \text {-level: } 1 \text { inpatient }(0.5 \%) \text {, } \\
1 \text { outpatient }(0.3 \%)\end{array}$ \\
\hline $\begin{array}{l}\text { Purger et } \\
\quad \text { al., } 2017\end{array}$ & $\begin{array}{l}\text { Retrospective study } \\
\text { using data from the } \\
\text { HCUP SID, SASD, } \\
\text { \& SEDD in FL, NY, } \\
\text { \& CA }\end{array}$ & Multiple & Not specified & $\begin{array}{l}\text { 50,131 patients: } 3135 \\
\text { ambulatory, 46,996 } \\
\text { inpatient }\end{array}$ & No & No & $\begin{array}{l}51(1.6 \%) \text { outpatients } \\
\text { readmitted, } 5(0.2 \%) \\
\text { underwent reoperation; } \\
1778(3.8 \%) \text { inpatients } \\
\text { readmitted, } 200(0.4 \%) \\
\text { underwent reoperation }\end{array}$ \\
\hline $\begin{array}{l}\text { McClelland } \\
\text { et al., } \\
2017\end{array}$ & $\begin{array}{l}\text { Retrospective cohort } \\
\text { study using the NIS } \\
\text { from 2001-2012 \& } \\
\text { the HCUP SASD for } \\
\text { NJ for 2003-2012 }\end{array}$ & Multiple & $1 \& 2$ & $\begin{array}{l}257,398 \text { inpatients, } 2016 \\
\text { outpatients; propen- } \\
\text { sity score matching } \\
\text { used to adjust analy- } \\
\text { sis: } 10,080 \text { patients: } \\
8064 \text { inpatients, } 2016 \\
\text { outpatients }\end{array}$ & No & No & $\begin{array}{l}14 \text { postop complications } \\
\text { assessed in propensity } \\
\text { score-matched analysis } \\
\text { of NIS \& NJ SASD to } \\
\text { examine impact of ACDF; } \\
\text { no specified complication } \\
\text { rate }\end{array}$ \\
\hline
\end{tabular}


TABLE 4. Literature studies comparing inpatient and outpatient ACDF procedures

\begin{tabular}{|c|c|c|c|c|c|c|c|}
\hline \multirow[b]{2}{*}{$\begin{array}{c}\text { Authors \& } \\
\text { Year }\end{array}$} & \multirow[b]{2}{*}{ Study Type } & \multirow[b]{2}{*}{ No. of Surgeons } & \multirow[b]{2}{*}{$\begin{array}{l}\text { Surgical } \\
\text { Levels }\end{array}$} & \multirow[b]{2}{*}{ No. of Patients } & \multicolumn{3}{|c|}{ Analysis of Outcome Parameters } \\
\hline & & & & & $\begin{array}{l}\text { Reduced } \\
\text { Pain }\end{array}$ & Fusion & Complication Rate \\
\hline $\begin{array}{l}\text { Present } \\
\text { study, } \\
2018\end{array}$ & Retrospective & Single & $1-4$ & $\begin{array}{l}1123 \text { patients: } 560 \\
\text { outpatients, } 563 \\
\text { inpatients }\end{array}$ & Yes & Yes & $\begin{array}{l}\text { Overall: } 3.21 \% \text {; outpatient } \\
4.15 \% \text {, inpatient } 3.17 \% \neq\end{array}$ \\
\hline
\end{tabular}

$\mathrm{CA}=$ California; FL = Florida; HCUP = Healthcare Cost and Utilization Project; NJ = New Jersey; NY = New York; SASD = State Ambulatory Surgery and Services Databases; SEDD = State Emergency Department Databases; SID = State Inpatient Databases.

All studies had level III evidence.

* Ninety-six percent of patients had 1 or 2 surgical levels.

$\dagger$ Inpatients were a meta-analysis-derived comparison group.

$\ddagger$ No statistical significance between the inpatient and outpatient groups, $p=0.424$.

A recent study by Martin and associates analyzed risk factors that influence the outcome of inpatient and outpatient single-level ACDF. ${ }^{18}$ An ASA physical status class III or IV, current dialysis, current corticosteroid use, recent sepsis, and operative times longer than 120 minutes were each independent risk factors for complications in the multivariate analysis. After propensity score matching to control for comorbidities, there were no significant differences in the complication rates between inpatients and outpatients, and outpatient treatment was not a risk factor for complications in the multivariate analysis. This result is consistent with the findings of McGirt and associates, who showed that an ASA class III or higher, chronic steroid use, hypertension, and male sex were risk factors for postdischarge complications..$^{21}$

Smoking did not affect the complication rate, nonunion rate, or LOS after surgery in our study. Luszczyk and colleagues found no statistically significant difference in fusion status between smokers and nonsmokers who had undergone a single-level ACDF with allograft and a locked anterior cervical plate. ${ }^{17}$

Diabetes is one of the most common comorbidities in patients undergoing ACDF. ${ }^{1}$ In our study, there was a higher rate of diabetes mellitus in the inpatients, and the patients with diabetes stayed in the hospital significantly longer. This finding is consistent with a recent retrospective analysis of prospectively collected data from the NSQIP, which associated insulin-dependent diabetes with increased total LOS. ${ }^{23}$

\section{Levels of Surgery}

In the outpatient group, significantly more patients had 1- and 2-level surgeries, whereas inpatients underwent 3and 4-level procedures more often. This was an expected observation corroborating data in the literature. Fu and colleagues showed that outpatients are less likely to undergo multilevel surgery. ${ }^{10} \mathrm{~A}$ recent multicenter meta-analysis of outpatient ACDF revealed that nearly two-thirds of outpatients underwent single-level fusion with virtually none undergoing $\mathrm{ACDF}$ at 3 or more levels, as well as an overall complication rate of $1.8 \% .{ }^{19}$ Our study is the first to establish 3-level surgery as a standard procedure in the outpatient setting given that one-fifth of our outpatient cohort had 3-level surgery; all other studies have concentrated on 1- and 2-level surgeries.

\section{Fusion}

Nonunion occurred in 5 of our patients $(0.45 \%)$. Two outpatients and 3 inpatients had pseudarthrosis. Two were treated with bone stimulators, and fusion occurred over 6 and 8 months' time, respectively, and was confirmed on CT scanning. Three patients underwent reoperation. The use of anterior cervical plating has been suggested to increase arthrodesis rates and decrease subsidence, making allograft an attractive option. For instrumented 1-level fusions, Samartzis and associates reported $100 \%$ arthrodesis with intervertebral cage allograft compared with $90.3 \%$ arthrodesis with autograft, although the difference between the two was not statistically significant. ${ }^{26} \mathrm{In}$ another study, the fusion rate was $100 \%$ in the allograft group and $90.3 \%$ in the autograft group, again with no statistically significant difference $(\mathrm{p}>0.05))^{15}$ The largest meta-analysis so far showed a fusion rate of $92.1 \%$ for ACDF. ${ }^{9}$ The cases in studies by Silvers and associates ${ }^{29}$ and Liu and colleagues ${ }^{16}$ were noninstrumented, and Adamson and colleagues did not specify which graft was used for fusion. ${ }^{1}$ Fraser and Härtl showed that, regardless of the number of levels fused, the use of an anterior cervical plate system significantly increases the fusion rate. ${ }^{9}$ Our experience of a high rate of fusion utilizing bone allografts corroborates this finding.

\section{Complications}

In our series, complications occurred in $3.6 \%$ of patients, with no significant difference in the complication rate between outpatients $(4.1 \%)$ and inpatients (3.0\%). Our complication rates are slightly higher than those in some previous studies comparing the outcomes of inpatient versus outpatient ACDF, yet they are lower than the complication rates reported by Fountas et al. ${ }^{7}$ and Stieber et al. ${ }^{32}$ There are 2 main reasons for this. First is our inclusion of nonunion (long-term complication) and temporary swallowing difficulties as complications. Excluding these complications would lower our rate of permanent complications to $2.5 \%$. Second, previous studies analyzed either 1- or 2-level ACDF or mostly 1- and 2-level ACDF with 
only a small number of 3-level surgeries. Nonetheless, in our series, the rate of complications in both settings was relatively low and no deaths were observed. In addition, we were fortunate not to experience any vascular, esophageal, nerve, or dural injuries.

In our study, $21.9 \%$ had 3-level surgery and the results showed that the complication rate is generally higher for 3and 4-level surgery than for 1-level and 2-level surgery ( $p$ $<0.001$, chi-square test). Furthermore, patients undergoing 3-level ACDF had significantly more complications in the outpatient setting than in the inpatient setting, whereas the findings were opposite for 4-level ACDF. The reliability of these differences is questionable, however, given the small number of cases. In the literature, multilevel ACDF has been shown to have an increased complication rate, and the rate rises with the number of segments fused..$^{14,35}$

Overall, $1.8 \%$ of patients who had undergone 1-level surgery and $2.8 \%$ of those who had undergone 2-level surgery experienced complications. Outpatient 1-level surgery had a complication rate of $2 \%$, and 1- and 2-level outpatient surgery together had a rate of $3.16 \%$, which is comparable to the findings of McGirt and associates. ${ }^{21}$ For $1-$ and 2-level surgery, 3 studies of the NSQIP database showed a lower rate of postoperative complications in the outpatient cohort, ${ }^{10,13,21}$ while the study by Adamson and associates, ${ }^{1}$ like ours, showed that all 90-day surgical morbidity was similar between outpatient and inpatient cohorts for 1- and 2-level ACDF. A recent 12-year nationwide inpatient analysis and 10-year single-state outpatient analysis of more than 250,000 total patients who had undergone 1- and 2-level surgery indicated that outpatient ACDF may yield fewer perioperative complications than inpatient ACDF, including durotomy, hematoma, paraplegia, respiratory complications, and anemia. ${ }^{20}$ This same study reported that ACDF performed on an outpatient basis was $19 \%$ less likely to result in an intraoperative durotomy and $86 \%$ less likely to result in a postoperative hematoma or seroma. These findings may be attributable to potential reporting bias between inpatient and outpatient centers given that hospitals (unlike ambulatory centers) are incentivized to report comorbidities and complications. ${ }^{20}$ Another potential explanation may be the significantly greater proportion of Medicare patients in the inpatient group since Medicare patients are more likely to have medical problems and associated comorbidities and to require longer hospitalizations. $^{20,37}$

A major factor contributing to the reluctance of surgeons to perform ACDF in the outpatient setting is the potential complication of airway compromise as a result of airway swelling or postoperative hematoma. But this complication is almost always recognizable within the first 4 hours after surgery, well within the time frame of perioperative observation in the ambulatory surgery setting. ${ }^{21}$ Our study included 9 patients with postoperative hematomas who underwent revision, and there were no permanent deficits. Close monitoring of outpatients for 6 hours postoperatively and then close daily follow-up via phone interview for 4 postoperative days allowed for the detection of all patients with this complication in a timely fashion. Fountas and associates, ${ }^{7}$ who analyzed the complications of ACDF, postulated that the development of isolated postoperative dysphagia was the most common complication (9.5\%), followed by postoperative hematoma (5.6\%), symptomatic recurrent laryngeal nerve palsy $(3.1 \%)$, dural penetration $(0.5 \%)$, esophageal perforation $(0.3 \%)$, Horner syndrome $(0.1 \%)$, instrumentation back-out $(0.1 \%)$, and superficial wound infection $(0.1 \%)$.

Our rates for the 2 most common complications reported in the literature were significantly lower, with only $0.8 \%$ of patients developing hematoma and $0.62 \%$ developing swallowing difficulties. Wound infection $(0.98 \%)$ and Horner syndrome $(0.45 \%)$ occurred at a slightly higher rate. The slight increase in wound infections could be a result of the associated comorbidities, which make patients more prone to developing infection. Because of this potential, we now universally apply vancomycin 1 hour before surgery in an attempt to decrease or eliminate this complication. Compared with the results of Adamson and associates, ${ }^{1}$ we had a greater number of neck hematomas, which needed revision surgery (3 vs 9), and more infections (3 vs 11), but none of our patients needed exploratory surgery to correct the swallowing difficulty (as opposed to 16 patients in the Adamson cohort). Silvers et al. ${ }^{29}$ and McGirt et al. ${ }^{21}$ did not report neck hematoma as a complication, whereas Liu et al. ${ }^{16}$ described it as a complication in 1 patient in their cohort. Khanna et al. ${ }^{13}$ reported $0.5 \%$ of inpatients with bleeding as a postoperative complication, as well as $0.6 \%$ of inpatients and $0.3 \%$ of outpatients with surgical site infection. In the 30-day morbidity analysis by Martin and associates, ${ }^{18}$ there were 5 deaths. Furthermore, the same study described, among other complications, postoperative surgical site infection in $0.48 \%$ of patients, unplanned intubation in $0.4 \%$, and wound complications in $0.6 \%$, with a reoperation rate of $1.2 \%$ in the first 30 days following ACDF. ${ }^{18}$ In the study by Khanna and colleagues, $0.2 \%$ of inpatients and $0.1 \%$ of outpatients died..$^{13}$

Several groups of investigators have concluded that ACDF can be safely performed in the outpatient setting with a sufficient postoperative observation period of up to 4 hours. ${ }^{11,16,27}$ Our protocol further increases postoperative observation to 6 hours, adding an additional layer of safety. Numerous studies have verified the safety of outpatient ACDF surgery. 3,4,6,19,24,28,33,34,36 The procedure performed in an ambulatory setting is not inferior to inpatient surgery in terms of mortality, 30-day emergency department visit rates, 30-day readmission rates, and 30-day reoperation rates and is less costly than inpatient ACDF in terms of actual costs and 90-day bundled charges. ${ }^{25}$ Nonetheless, a recent risk-complication analysis of studies on cervical spine surgery performed in ambulatory surgery centers has revealed that at least some of these studies demonstrated an inherent conflict of interest and did not report major morbidity and mortality rates for outpatient procedures in a nonbiased way, which must be considered..$^{23}$

A study by Silvers and associates comparing outpatient versus inpatient ACDF in 103 consecutive patients showed equal complication rates $(2 \%)$ in both groups. ${ }^{29}$ Similarly, a study by Liu and colleagues involving 109 patients did not show any significant differences in outcomes between outpatient and inpatient groups. ${ }^{16}$ McGirt and associates also verified the safety of outpatient ACDF, with those who had undergone outpatient ACDF having 58\% lower 
odds of experiencing major morbidity and $80 \%$ lower odds of a return to the operating room within 30 days. ${ }^{21}$ Villavicencio and associates evaluated outpatient and 23-hour admissions for $\mathrm{ACDF}$ and plating $(\mathrm{ACDF}+\mathrm{P})$ and compared their numbers to those in a historical cohort treated as inpatients, finding no difference in the complication rates. ${ }^{36}$ Another study showed that among 1-level and 2-level ACDF cases, the rate of any postoperative complication was significantly lower in the outpatient group than in the inpatient cohort. ${ }^{10}$ Our study strongly supports the findings of other authors who assert that the risk of complications is not higher in the outpatient setting than in the inpatient setting.

\section{Costs}

The increased use of outpatient ACDF instead of inpatient ACDF represented a way to decrease payers' costs by more than $\$ 100$ million in $1996 .{ }^{29}$ Adjusting for the utilization of ACDF in 2012, the cost savings may be as high as $\$ 400$ million annually. ${ }^{21}$ While an acute care episode is the largest contributor to the cost of spine surgery, the greatest variability in cost occurs with the wide range in complication rates, hospital readmissions, and reoperations during the post-acute care period. ${ }^{21}$ The recent study of Purger et al. ${ }^{25}$ revealed that actual costs associated with the initial operation, as well as 90-day cumulative charges (charges associated with the initial surgery plus all emergency department visits, hospital readmissions, and revisits to ambulatory surgery centers), were significantly lower for outpatient ACDF than for inpatient ACDF. Overall charges were significantly lower for ambulatory $\operatorname{ACDF}(\$ 33,362.51$ vs $\$ 74,667.04, \mathrm{p}<0.0001) .{ }^{25}$

\section{Limits of This Study}

The limitations of this study include its retrospective design, our inability to exclude its selection bias, and the relatively short mean follow-up period (slightly more than 2 years). This single-surgeon experience may limit the ability to generalize results to the entire population undergoing ACDF. Furthermore, patients with cervical radiculopathy cannot be differentiated from those with myelopathy, and outcomes can differ in these 2 patient populations. ${ }^{21}$

\section{Conclusions}

Anterior cervical discectomy and fusion is safe to perform on an outpatient basis for 1 or 2 levels, with a high rate of successful fusion and pain reduction, a low complication rate, and no deaths. Three-level ACDF can also be performed as a standard procedure in an outpatient surgery center with close monitoring. Close follow-up should be done for at least 6 hours postoperatively with the drain in position. Additional consideration needs to be given to patients with comorbidities, such as diabetes mellitus. To decrease the cost of care, surgeons can safely consider performing ACDF in an ambulatory surgery center. The comparable clinical and radiological outcomes and the same complication rates for inpatients and outpatients may favor performing ACDF procedures in the outpatient setting, whenever medically and logistically possible, to lower costs.

\section{Acknowledgments}

We thank Ms. Julie Yamamoto, MA, for editing this manuscript, Ms. Kristina Kralik for statistical expertise, and Mr. Andrew J. Gienapp for copy editing, preparation of the manuscript and figures for publishing, and publication assistance.

\section{References}

1. Adamson T, Godil SS, Mehrlich M, Mendenhall S, Asher AL, McGirt MJ: Anterior cervical discectomy and fusion in the outpatient ambulatory surgery setting compared with the inpatient hospital setting: analysis of 1000 consecutive cases. J Neurosurg Spine 24:878-884, 2016

2. Arnold PM, Rice LR, Anderson KK, McMahon JK, Connelly LM, Norvell DC: Factors affecting hospital length of stay following anterior cervical discectomy and fusion. Evid Based Spine Care J 2:11-18, 2011

3. Baird EO, Egorova NN, McAnany SJ, Qureshi SA, Hecht AC, Cho SK: National trends in outpatient surgical treatment of degenerative cervical spine disease. Global Spine J 4:143-150, 2014

4. Ban D, Liu Y, Cao T, Feng S: Safety of outpatient anterior cervical discectomy and fusion: a systematic review and meta-analysis. Eur J Med Res 21:34, 2016

5. Cloward RB: The anterior approach for removal of ruptured cervical disks. 1958. J Neurosurg Spine 6:496-511, 2007

6. Erickson M, Fites BS, Thieken MT, McGee AW: Outpatient anterior cervical discectomy and fusion. Am J Orthop 36:429-432, 2007

7. Fountas KN, Kapsalaki EZ, Nikolakakos LG, Smisson HF, Johnston KW, Grigorian AA, et al: Anterior cervical discectomy and fusion associated complications. Spine (Phila Pa 1976) 32:2310-2317, 2007

8. Fowler SB, Anthony-Phillips P, Mehta D, Liebman K: Health-related quality of life in patients undergoing anterior cervical discectomy fusion. J Neurosci Nurs 37:97-100, 2005

9. Fraser JF, Härtl R: Anterior approaches to fusion of the cervical spine: a metaanalysis of fusion rates. J Neurosurg Spine 6:298-303, 2007

10. Fu MC, Gruskay JA, Samuel AM, Sheha ED, Derman PB, Iyer S, et al: Outpatient anterior cervical discectomy and fusion is associated with fewer short-term complications in one-and two-level cases: a propensity-adjusted analysis. Spine (Phila Pa 1976) 42:1044-1049, 2017

11. Garringer SM, Sasso RC: Safety of anterior cervical discectomy and fusion performed as outpatient surgery. J Spinal Disord Tech 23:439-443, 2010

12. Helseth $\varnothing$, Lied B, Halvorsen CM, Ekseth K, Helseth E: Outpatient cervical and lumbar spine surgery is feasible and safe: a consecutive single center series of 1449 patients. Neurosurgery 76:728-738, 2015

13. Khanna R, Kim RB, Lam SK, Cybulski GR, Smith ZA, Dahdaleh NS: Comparing short-term complications of inpatient versus outpatient single-level anterior cervical discectomy and fusion: an analysis of 6940 patients using the ACSNSQIP database. Clin Spine Surg [epub ahead of print], 2017

14. Koller H, Hempfing A, Ferraris L, Maier O, Hitzl W, MetzStavenhagen P: 4- and 5-level anterior fusions of the cervical spine: review of literature and clinical results. Eur Spine J 16:2055-2071, 2007

15. Leven D, Cho SK: Pseudarthrosis of the cervical spine: risk factors, diagnosis and management. Asian Spine J 10:776786, 2016

16. Liu JT, Briner RP, Friedman JA: Comparison of inpatient vs. outpatient anterior cervical discectomy and fusion: a retrospective case series. BMC Surg 9:3, 2009

17. Luszczyk M, Smith JS, Fischgrund JS, Ludwig SC, Sasso RC, Shaffrey CI, et al: Does smoking have an impact on fusion 
rate in single-level anterior cervical discectomy and fusion with allograft and rigid plate fixation? Clinical article. J Neurosurg Spine 19:527-531, 2013

18. Martin CT, Pugely AJ, Gao Y, Mendoza-Lattes S: Thirtyday morbidity after single-level anterior cervical discectomy and fusion: identification of risk factors and emphasis on the safety of outpatient procedures. J Bone Joint Surg Am 96:1288-1294, 2014

19. McClelland S III, Oren JH, Protopsaltis TS, Passias PG: Outpatient anterior cervical discectomy and fusion: A metaanalysis. J Clin Neurosci 34:166-168, 2016

20. McClelland S III, Passias PG, Errico TJ, Bess RS, Protopsaltis TS: Inpatient versus outpatient anterior cervical discectomy and fusion: a perioperative complication analysis of 259,414 patients from the Healthcare Cost and Utilization Project databases. Int J Spine Surg 11:11, 2017

21. McGirt MJ, Godil SS, Asher AL, Parker SL, Devin CJ: Quality analysis of anterior cervical discectomy and fusion in the outpatient versus inpatient setting: analysis of 7288 patients from the NSQIP database. Neurosurg Focus 39(6):E9, 2015

22. Peolsson A, Peolsson M: Predictive factors for long-term outcome of anterior cervical decompression and fusion: a multivariate data analysis. Eur Spine J 17:406-414, 2008

23. Phan K, Kim JS, Lee N, Kothari P, Cho SK: Impact of insulin dependence on perioperative outcomes following anterior cervical discectomy and fusion. Spine (Phila Pa 1976) 42:456-464, 2017

24. Pugely AJ, Martin CT, Gao Y, Mendoza-Lattes SA: Outpatient surgery reduces short-term complications in lumbar discectomy: an analysis of 4310 patients from the ACSNSQIP database. Spine (Phila Pa 1976) 38:264-271, 2013

25. Purger DA, Pendharkar AV, Ho AL, Sussman ES, Yang L, Desai M, et al: Outpatient vs inpatient anterior cervical discectomy and fusion: a population-level analysis of outcomes and cost. Neurosurgery [epub ahead of print], 2017

26. Samartzis D, Shen FH, Goldberg EJ, An HS: Is autograft the gold standard in achieving radiographic fusion in one-level anterior cervical discectomy and fusion with rigid anterior plate fixation? Spine (Phila Pa 1976) 30:1756-1761, 2005

27. Sasso RC, Ruggiero RA Jr, Reilly TM, Hall PV: Early reconstruction failures after multilevel cervical corpectomy. Spine (Phila Pa 1976) 28:140-142, 2003

28. Sheperd CS, Young WF: Instrumented outpatient anterior cervical discectomy and fusion: is it safe? Int Surg 97:8689,2012

29. Silvers HR, Lewis PJ, Suddaby LS, Asch HL, Clabeaux DE, Blumenson LE: Day surgery for cervical microdiscectomy: is it safe and effective? J Spinal Disord 9:287-293, 1996

30. Singh P, Kumar A, Shekhawat V: Comparative analysis of interbody cages versus tricortical graft with anterior plate fixa- tion for anterior cervical discectomy and fusion in degenerative cervical disc disease. J Clin Diagn Res 10:RC05-RC08, 2016

31. Smith GW, Robinson RA: The treatment of certain cervicalspine disorders by anterior removal of the intervertebral disc and interbody fusion. J Bone Joint Surg Am 40-A:607-624, 1958

32. Stieber JR, Brown K, Donald GD, Cohen JD: Anterior cervical decompression and fusion with plate fixation as an outpatient procedure. Spine J 5:503-507, 2005

33. Tally WC, Tarabadkar S, Kovalenko BV: Safety and feasibility of outpatient ACDF in an ambulatory setting: a retrospective chart review. Int J Spine Surg 7:e84-e87, 2013

34. Trahan J, Abramova MV, Richter EO, Steck JC: Feasibility of anterior cervical discectomy and fusion as an outpatient procedure. World Neurosurg 75:145-148, 43-44, 2011

35. Veeravagu A, Cole T, Jiang B, Ratliff JK: Revision rates and complication incidence in single- and multilevel anterior cervical discectomy and fusion procedures: an administrative database study. Spine J 14:1125-1131, 2014

36. Villavicencio AT, Pushchak E, Burneikiene S, Thramann JJ: The safety of instrumented outpatient anterior cervical discectomy and fusion. Spine J 7:148-153, 2007

37. Waits SA, Reames BN, Sheetz KH, Englesbe MJ, Campbell DA Jr: Anticipating the effects of Medicaid expansion on surgical care. JAMA Surg 149:745-747, 2014

\section{Disclosures}

No funding was used for this study. Mr. Mullins, Dr. Pojskić, and Dr. Arnautović have no financial relationships to disclose. Dr. Boop serves as a consultant for Medtronic.

\section{Author Contributions}

Conception and design: Arnautović, Pojskić, Boop. Acquisition of data: Arnautović, Mullins, Pojskić. Analysis and interpretation of data: Arnautović, Pojskić, Boop. Drafting the article: Arnautović, Mullins, Pojskić. Critically revising the article: Arnautović, Pojskić, Boop. Reviewed submitted version of manuscript: Arnautović, Pojskić, Boop. Approved the final version of the manuscript on behalf of all authors: Arnautović. Statistical analysis: Arnautović, Mullins, Pojskić.

\section{Correspondence}

Kenan Arnautović: Semmes Murphey Neurologic \& Spine Institute, University of Tennessee Health Science Center, Memphis, TN. kenanarnaut@yahoo.com. 